\title{
Déficit em Transações Correntes, Movimentos de Capital e Ataques Especulativos: Uma Abordagem Estruturalista das Recentes Crises Cambiais na América Latina
}

\author{
Marcelo Curado \\ Gabriel Porcile
}

\begin{abstract}
Prof. Adjunto do Departamento de Economia da UFPR
Prof. Adjunto do Departamento de Economia da UFPR
\end{abstract}

e Pesquisador do CNPq

\begin{abstract}
RESUMO
O objetivo deste trabalho é elaborar um modelo teórico sobre o papel dos déficits estruturais em transações correntes e da capacidade limitada de absorção de ativos externos como elementos presentes em crises cambiais de economias emergentes. O modelo terá como referência as recentes crises ocorridas na América Latina, especificamente a crise mexicana de 1994 e brasileira de 1999. Pretende-se, portanto, incorporar ao debate algumas especificidades da região que têm sido negligenciadas, ou incorporadas de forma apenas parcial, pela literatura estabelecida sobre crises cambiais. O modelo deverá ilustrar o argumento de que as causas para os recentes ataques especulativos na região encontram vinculações - além dos aspectos financeiros destacados pela literatura estabelecida - com o grau de competitividade externa da economia e seu grau de desenvolvimento tecnológico.
\end{abstract}

\section{PALAVRAS-CHAVE}

hiato tecnológico, fluxos de capitais, crises cambiais, América Latina

ABSTRACT

This work aims to develop a theoretical model of the role that structural deficit in current account, as well as a limited capacity of absorption of financial capital, play in exchange rate crisis in developing countries. The model is specifically framed in the light of the experience of exchange rate crisis in Latin America, especially that of Brazil (1999) and Mexico (1994). The model includes key features of the Latin American economies which have been neglected or taken into account only partially in the current literature on external crisis. In particu-

lar, it is argued that recent speculative attacks on some Latin American currencies are related - along with the financial aspects usually highlighted by the existing literature - to competitiveness and technological development.

KEY WORDS

tecnological gap, capital flows, currency crisis, Latin America

JEL Classification

G00, GI5, F32

EST. ECON., SÃO PAULO, V. 34, N. 3, P. 515-551, JULHO-SETEMBRO 2004 


\section{INTRODUÇÃO}

O objetivo deste trabalho é elaborar um modelo teórico sobre o papel dos déficits crônicos em transaçóes correntes e da capacidade limitada de atração de ativos externos como elementos presentes em crises cambiais de economias emergentes. O argumento central é que a combinação destes elementos - num contexto de fixação da taxa de câmbio pelo Banco Central estabelece as condiçóes necessárias para a ocorrência de um ataque especulativo.

O modelo terá como referência as recentes crises ocorridas na América Latina, especificamente a crise mexicana de 1994 e brasileira de 1999. Pretendese, portanto, incorporar ao debate algumas especificidades da região que têm sido negligenciadas, ou incorporadas de forma apenas parcial, pela literatura estabelecida sobre crises cambiais. $\mathrm{O}$ modelo deverá ilustrar $\mathrm{o}$ argumento de que as causas para os recentes ataques especulativos na região encontram vinculações - além dos aspectos financeiros destacados pela literatura estabelecida - com o grau de competitividade externa da economia e seu grau de desenvolvimento tecnológico.

O trabalho encontra-se estruturado da seguinte forma. Na seção 1 será apresentada uma breve introdução ao debate existente na literatura convencional sobre crises cambiais. O objetivo da seção é estabelecer quais são os avanços desta literatura, assim como permitir ao leitor identificar a natureza da proposta deste trabalho. A seção 2 apresenta algumas evidências empíricas sobre o comportamento das transaçóes correntes e da capacidade limitada de atração de capitais. A seção 3 inicia a construção do modelo. Na subseção 3.1 será elaborada uma versão estruturalista do comportamento das transaçôes de natureza comercial do balanço de pagamentos. O resultado de transações comerciais livres será a geração de um desequilíbrio crônico nas economias em desenvolvimento. Na subseção 3.2 será apresentado um modelo de alocação de portfólio global que indicará o comportamento da esfera financeira do balanço de pagamentos. A subseção 3.3 analisa o comportamento conjunto do lado comercial e financeiro do balanço de pagamentos, demonstrando suas inter-relaçóes e como, em última instância, o crônico déficit em transações correntes, característico das economias em 
desenvolvimento, se constitui num dos aspectos essenciais para o entendimento dos movimentos de realocação de portfólio em nível global que geraram os recentes ataques especulativos. A última seção é dedicada à apresentação das conclusões do trabalho.

\section{LITERATURA SOBRE CRISES CAMBIAIS: UMA BREVE IN- TRODUÇÃO}

Esta seção apresentará, de forma breve, uma introdução à literatura sobre o tema. O objetivo da seção é estabelecer os avanços desta literatura no que se refere à incorporação de novos elementos na explicação dos ataques especulativos, assim como permitir ao leitor identificar a natureza da proposta deste trabalho.

De uma forma geral, seguindo, entre outros, Krugman (1998), Corsetti, Pesenti e Roubini (1998) e Andrade e Falcão (1998), a literatura sobre a ocorrência de ataques especulativos pode ser organizada em três gerações.

Os modelos de "primeira geração", com destaque para os trabalhos de Krugman (1979) e Flood e Garber (1984), argumentam que a crise cambial é fruto de problemas na gestão de política macroeconômica. Nestes trabalhos, o fator-chave para a explicação do ataque especulativo é a ampliação do crédito doméstico relacionada à monetização de crescentes déficits fiscais. A expansão monetária gera uma expectativa de ampliação da inflação doméstica. É justamente esta expectativa, num contexto de fixação da taxa de câmbio pela Autoridade Monetária, que desencadeia o ataque especulativo. Os agentes percebem que a manutenção da moeda local vis-à-vis à moeda estrangeira acarreta numa perda de valor relativo. A forma racional de defender-se desta perda dá-se por meio da troca de moeda doméstica por moeda estrangeira. A crise cambial é decorrente da incompatibilidade da monetização dos déficits públicos, num contexto de fixação da taxa de câmbio. Trata-se, portanto, como apontam Andrade e Falcão (1998), de um problema de gestão de política macroeconômica. 
A chamada literatura de "segunda geração", em que se destaca o trabalho de Obstfeld (1994), sustenta, da mesma forma que os modelos de "primeira geração", que a crise cambial é fruto de problemas na gestão de política macroeconômica. Esta abordagem se diferencia dos modelos canônicos basicamente por dar ao governo a possibilidade de escolha - com base na análise de custo-benefício social - em manter ou não fixas as taxas de câmbio. $\mathrm{O}$ ataque ocorre sempre que os agentes antecipem que os custos sociais são superiores aos benefícios do regime cambial em vigor. Isto pode acontecer em razão tanto de uma piora nos indicadores macroeconômicos quanto de uma alteração auto-sustentada nas expectativas dos agentes. No entanto, mesmo neste segundo caso, a alteração das expectativas é igualmente derivada de um enfraquecimento dos indicadores macroeconômicos. ${ }^{1}$

Em suma, tanto a literatura de "primeira geração quanto os modelos de "segunda geração" consideravam os problemas na gestão de política macroeconômica como causadores dos ataques especulativos. Não obstante, como apontam, entre outros, Krugman (1998) e Corsetti, Pesenti e Roubini (1998), estes indicadores macroeconômicos dos países latino-americanos, com destaque para o "sucesso" mexicano do início dos anos 90, mas sobretudo dos países do sudeste da Ásia, não se encontravam fragilizados.

O sudeste asiático exibia uma situação invejável do ponto de vista dos principais indicadores macroeconômicos: elevadas taxas de crescimento, inflação baixa e estabilidade fiscal. A Coréia do Sul, paradigma do processo de upgrading destas economias, por exemplo, apresentou taxas de crescimento do PIB de 8,6\%, 8,9\% e 7,1\% nos anos de 1994 a 1996, enquanto o índice de preços ao consumidor manteve-se, neste período, na casa de um dígito. A Tailândia, outro exemplo de sucesso, apresentou, no mesmo período, taxas de crescimento do PIB de 8,9\%, 9,1\% e 7,7\%. As variações nos índices de preços ao consumidor, neste caso, apresentavam-se em torno de $5 \%$ ao ano. No que tange à situação fiscal, tanto a Coréia do Sul quanto a Tailândia apresentavam superávits primários em suas contas públicas ao longo dos anos 90.

1 Os principais indicadores macroeconômicos focalizados pela literatura de "segunda geração" são: taxa de crescimento, desemprego e inflação. 
A situação da América Latina não era a mesma do sudeste asiático, porém não deixava de ser satisfatória. A consolidação dos programas de combate à inflação e a retomada do crescimento em meados dos anos 90 no Brasil se constituíam em indicadores macroeconômicos positivos para a região. $\mathrm{O}$ mesmo pode se dizer da economia mexicana, vista até poucos meses antes da crise de 1994 como exemplo de condução de política econômica e de estabilidade.

Neste cenário, a ocorrência de uma fuga maciça e abrupta de capitais, ou seja, de um ataque especulativo contra os países do sudeste asiático era um fenômeno improvável de acordo com os modelos de "primeira" e "segunda" geração. Não obstante, os anos 90 foram marcados por uma sucessão de ataques especulativos contra moedas de países emergentes da América Latina e do sudeste da Ásia.

Neste sentido, Krugman (1998) e Corsetti, Pesenti e Roubini (1998) argumentam que os modelos "canônicos" e de "segunda geração" não são capazes de explicar satisfatoriamente os recentes ataques especulativos ocorridos no sudeste asiático e que posteriormente atingiram a Rússia e a América Latina, já que os problemas macroeconômicos que explicam a ocorrência de uma crise cambial não se encontram presentes nestas crises.

Esta incapacidade tem motivado diversos pesquisadores a construírem modelos que sejam compatíveis com as características das crises recentes. Esta literatura tem seguido, em sua grande maioria, um caminho muito claro. Enquanto os modelos "canônicos" e de "segunda geração" utilizam-se da hipótese de mercados financeiros eficientes e entendem que a crise cambial é resultante de problemas na gestão de política macroeconômica, os trabalhos recentes, chamados de "terceira geração", partem da hipótese da existência de assimetria na distribuição de informações nos mercados financeiros - negando, portanto, a hipótese de mercados eficientes - e associam, em sua grande maioria, a ocorrência da crise cambial à verificação de uma "crise financeira”.

Esta literatura salienta que o fato de alguns agentes saberem mais do que outros gera diversos comportamentos, os quais, até então - sob a vigência 
da hipótese de eficiência dos mercados -, não se encontravam contemplados pela literatura econômica, tais como a possibilidade de seleção adversa, risco moral e comportamento de manada nos mercados financeiros. Estes elementos passam a ser incorporados como fatores decisivos na explicação dos ataques especulativos recentes.

Corsetti, Pesenti e Roubini (1998) e Krugman (1998), por exemplo, apresentam trabalhos nos quais a crise é gerada num ambiente com assimetria de informação e, portanto, onde a ocorrência de risco moral é plausível, em virtude de decisões de sobreinvestimento, capturando, desta forma, um dos elementos centrais na geração das crises recentes: a gestão financeira problemática que caracterizava as principais instituições asiáticas pré-crise.

Outra linha de pesquisa importante dos modelos de "terceira geração" é aquela que explica a sequiência de crises cambiais recentes como fruto de mecanismos de "contágio" em razão de comportamentos de manada. Exemplos desta linha de pesquisa encontram-se, entre outros, no trabalho de Calvo e Mendoza (2000).

Esta "evolução" da literatura internacional é, em grande medida, fruto de fenômenos concretos verificados no mercado cambial ao longo dos anos 90 . Com exceção dos modelos canônicos que pretendiam se constituir em "modelos gerais" de explicação para crises cambiais, os modelos de "segunda e terceira geração" são dedicados à interpretação de crises cambiais específicas.

Embora sejam inegáveis os avanços dos modelos de "terceira geração" na explicação dos ataques especulativos recentes, alguns elementos importantes para compreensão deste fenômeno, sobretudo no que se refere à explicação das crises cambiais ocorridas na América Latina nos anos noventa, ${ }^{2}$ ainda não foram incorporados de forma plena pela literatura. Em outras palavras, existem algumas especificidades da inserção internacional latino-americana que nos parecem importantes na explicação dos ataques especulativos ocorridos na região nos anos 90 e que não foram incorporadas, ou foram apenas de forma parcial, pela literatura de "terceira geração". Dentre elas, cabe des-

2 Estamos nos referindo especificamente aos ataques ocorridos contra o peso mexicano em 1994 e contra o real em 1999. 
tacar que a América Latina é caracterizada por recorrentes desequilíbrios em suas transações correntes. Por um lado, isto é fruto de sua capacidade limitada de competição que, em última instância, reflete o atraso tecnológico da região em relação às economias desenvolvidas e às economias emergentes que realizaram um upgrading tecnológico nas últimas décadas, como, por exemplo, as economias do sudeste asiático. Por outro lado, o pagamento de juros da dívida externa acumulada e as remessas de lucros e dividendos pela empresas multinacionais instaladas na região pressionam o resultado da balança de serviços.

Soma-se a este cenário a opção de política econômica, no caso brasileiro adotada entre 1994 e 1998, de promover a manutenção do controle do processo inflacionário por meio da ampliação do processo de abertura comercial e de forte valorização da taxa de câmbio real. O resultado concreto é a geração de déficits comerciais e a ampliação dos déficits em transações correntes.

A existência de desequilíbrios sistemáticos nas transações correntes da região se dá num contexto internacional onde os fluxos de capitais externos para as economias emergentes não são ilimitados. Isto é fruto, entre outros fatores, do caráter emergente destas economias e, portanto, do risco atribuído a elas durante o processo de alocação da riqueza financeira global. Ainda mais, a capacidade das economias emergentes de atrair capitais de curto prazo a partir de elevaçóes continuadas das taxas de juros tem-se demonstrado restrita, sobretudo em períodos de instabilidade no cenário financeiro internacional.

Este trabalho argumenta que os desequilíbrios sistemáticos nas transações correntes e o contexto de restrição dos fluxos de capital de curto prazo são fatores relevantes na explicação das recentes crises cambiais ocorridas na América Latina e que necessitam ser incorporados ao debate.

A próxima seção é dedicada à apresentação de algumas evidências empíricas sobre o caráter recorrente dos déficits em transações correntes e a capacidade limitação de atração de capitais na América Latina. 
2. DÉFICITS CRÔNICOS EM TRANSAÇÕES CORRENTES E A CAPACIDADE LIMITADA DE ATRAÇÃO DE CAPITAIS: OS "FATOS ESTILIZADOS”

O modelo teórico construído a partir da próxima seção busca incorporar o papel exercido pelos déficits crônicos em transações correntes e pela capacidade limitada de atrair capital na geração de crises cambiais na América Latina.

O Gráfico 1 apresenta os resultados do saldo em transaçôes correntes para alguns países selecionados da América Latina (Brasil, Argentina e México) e para a região como um todo. As informações estatísticas, obtidas da Comissão Econômica para América Latina e Caribe (CEPAL), evidenciam a recorrência de problemas crônicos no saldo em transações correntes para o período selecionado.

\section{GRÁFICO I - SALDO EM TRANSAÇÕES CORRENTES - PAÍSES SELE- CIONADOS - 1982-2002}

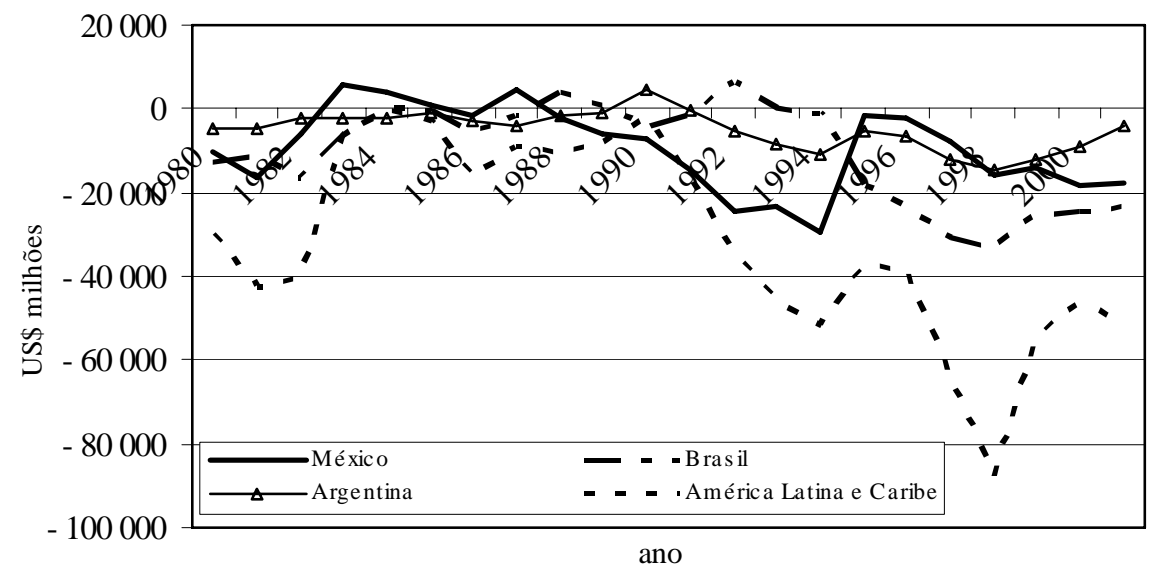

Fonte: International Financial Statistics - Fundo Monetário Internacional - Diversos Números.

A análise do gráfico permite verificar que nos anos 1990 o problema foi amplificado. A razão para este fato parece residir, entre outros determinantes, na utilização regimes de administração da taxa de câmbio que promoveram valorizações dos padrões monetários locais. México, Brasil e Argentina são 
exemplos de como as políticas de valorização cambial, utilizadas com intuito de combater processos inflacionários, acabaram ampliando os desequilíbrios externos, o que condicionou a política monetária, em especial a taxa de juros, as condições de liquidez internacional e a necessidade de atração de capitais de curto prazo. Em alguma medida, este tipo de observação corrobora a idéia de que o grau de competitividade externa da matriz produtiva destas economias é limitado e que o equilíbrio externo é fortemente dependente do comportamento da taxa de câmbio.

Outro elemento que será incorporado na explicação das crises cambiais é a capacidade limitada de atração de capitais pela região. Trata-se, na realidade, de uma característica que perpassa as economias dos países emergentes. $\mathrm{O}$ Gráfico 2 apresenta as flutuações das condições de liquidez do sistema financeiro internacional para estas economias. Períodos de expansão da liquidez internacional são seguidos por momentos de franca contração.

\section{GRÁFICO 2 - FLUXOS DE CAPITAL PARA ECONOMIAS EMER- GENTES - 1971- 2000 - EM US\$ BILHÕES}

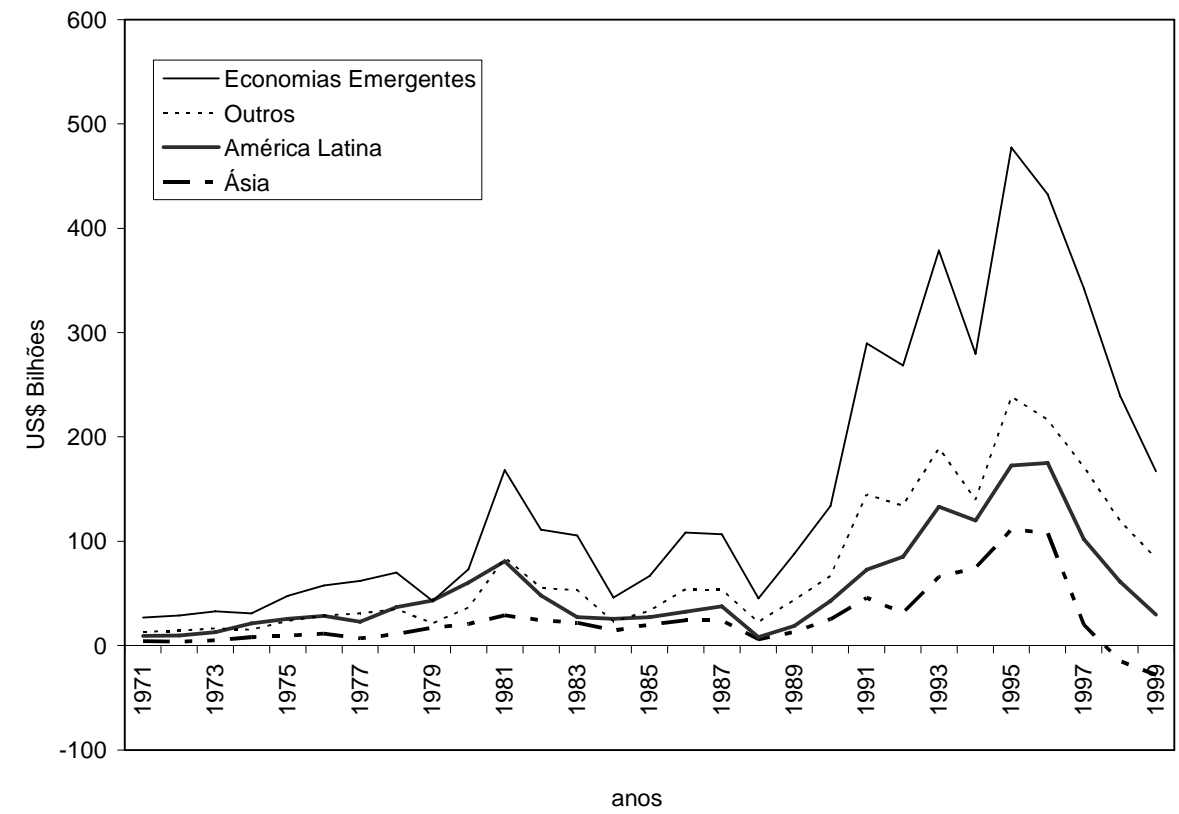

Fonte: International Financial Statistics - Fundo Monetário Internacional - Diversos Números. 
A utilização de instrumentos de política monetária, em específico a ampliação da taxa de juros doméstica, mostra-se também incapaz de reverter o comportamento das reservas internacionais em momentos de instabilidade nas economias emergentes. Conforme pode ser observado nos Gráficos 3 a 10, anexos, nos momentos que antecedem os ataques especulativos, a ampliação da taxa de juros doméstica, dada a relativa estabilidade dos juros internacional, e do diferencial de juros não são capazes de reverter o movimento de fuga de capitais para um conjunto de economias emergentes selecionadas.

\section{UM MODELO ESTRUTURALISTA PARA OS ATAQUES ESPECULA- TIVOS NA AMÉRICA LATINA}

A partir desta seção é iniciada a construção de um modelo estruturalista de interpretação dos ataques especulativos sofridos pelo México em 1994 e o Brasil em 1999. Trata-se de um modelo no qual a combinação dos crônicos déficits em transações correntes com a capacidade limitada de atração de capitais - num regime de câmbio fixo - fornece os elementos necessários para a geração de um ataque especulativo.

\subsection{Desenvolvimento Desigual de Tecnologia e Suas Implicaçóes Sobre o Equili- brio Comercial}

Nesta subseção estabeleceremos as relações entre o grau de desenvolvimento tecnológico e os resultados do saldo comercial, dando início à construção do modelo explicativo de crises cambiais. O trabalho será construído para dois blocos de países: desenvolvidos e em desenvolvimento. Este último representará uma estilização das particularidades latino-americanas apresentadas ao longo do trabalho. Iniciamos a apresentação a partir da definição dos elementos distintivos destes blocos.

Adota-se, aqui, que a distinção entre economias desenvolvidas e em desenvolvimento é derivada da capacidade diferenciada de geração e incorporação de progresso técnico. Como hipótese, as economias em desenvolvimento se limitam a incorporar - por meio de processos de aprendizagem e imitação - 
o progresso técnico produzido nas economias desenvolvidas. Em outras palavras, as economias em desenvolvimento não são produtoras de progresso técnico, papel desempenhado exclusivamente pelas economias desenvolvidas. Adota-se, ainda, como hipótese complementar que os processos de imitação e aprendizagem promovidos pelas economias em desenvolvimento são incapazes de absorver de forma plena o progresso tecnológico originado nas economias desenvolvidas. Isto implica a ocorrência de um hiato tecnológico de caráter permanente entre os dois blocos de países.

Estas hipóteses encontram sua justificativa teórica nos trabalhos da "velha" e "nova" CEPAL e na recente literatura evolucionista, à la Fagerberg (1988) e Verspagen (1994).

Prebisch (1948), em seu "Manifesto", 3 atribuía as diferenças de desenvolvimento econômico entre centro e periferia ao desenvolvimento e difusão desigual do progresso técnico em nível internacional. Esta hipótese permanece como elemento-chave dos estudos mais recentes da CEPAL, a chamada nova CEPAL, dentre os quais se destacam os importantes trabalhos de Fajnzylber (1983, 1988).

Esta hipótese não é, no entanto, uma exclusividade do pensamento cepalino. Os recentes modelos de crescimento evolucionista à la Fagerberg (1988) e Verspagen (1994) incorporam em sua agenda de pesquisa a hipótese de desenvolvimento e difusão assimétrica do progresso tecnológico entre países.

\subsubsection{Hiato Tecnológico Permanente: Uma Estilização}

Da subseção anterior, duas características essenciais são obtidas:

1. Apenas os países desenvolvidos são produtores de progresso técnico $\left(T_{d}\right)$. Assumimos, ainda, que o progresso técnico nos países desenvolvidos ocorre a uma taxa exógena constante $\rho$. Este suposto permite focar

3 Referimo-nos ao trabalho de Prebisch intitulado "Economic development of Latin America and its principal problems". Posteriormente, Albert Hirschman chamou o texto de "Manifesto Latino Americano". Atualmente, o texto é amplamente conhecido como "Manifesto". 
a análise da evolução do hiato tecnológico ${ }^{4}$ na absorção de tecnologia nas economias em desenvolvimento.

2. As economias em desenvolvimento apropriam-se do progresso tecnológico das economias desenvolvidas a partir de sua difusão internacional e de sua capacidade de absorção deste progresso por processos de imitação e aprendizado.

Se chamarmos de $\mu$ a capacidade de absorção do progresso tecnológico pelas economias em desenvolvimento derivado de seus processos de aprendizado e imitação, então o progresso técnico das economias em desenvolvimento $(T e)$ ao longo do tempo pode ser descrito como:

$$
\frac{d T e / d t}{T e}=\mu-\mu\left(\frac{T e}{T d}\right)
$$

Esta formatação, desenvolvida inicialmente por Fagerberg (1988), possui duas implicações importantes. Em primeiro lugar, a taxa de progresso tecnológico das economias em desenvolvimento encontra-se condicionada por sua capacidade de absorção do progresso tecnológico e pelo nível inicial do hiato tecnológico. Evidentemente, quanto mais desenvolvido o sistema de ciência e tecnologia na economia em desenvolvimento (maior o parâmetro $\mu$ ), mais rápido o processo de catching-up. Em segundo lugar, quanto mais distante da fronteira tecnológica, ou seja, quanto maior o hiato tecnológico, maior é a taxa de progresso tecnológico nas economias em desenvolvimento.

Desta forma, o hiato tecnológico $(H)$ entre as economias desenvolvidas e em desenvolvimento é descrito a partir de:

$$
\frac{d T d / d t}{T d}-\frac{d T e / d t}{T e}=\frac{d H / d t}{H}=\rho-\left[\mu-\mu\left(\frac{T e}{T d}\right)\right]
$$

4 Hiato tecnológico pode ser definido, seguindo a tradição neo-schumpeteriana, como a diferença existente, num determinado momento do tempo, entre o grau de desenvolvimento tecnológico para duas economias. De uma forma geral, a sua mensuração é realizada por meio da utilização de proxies como, por exemplo, a diferença entre o número de patentes registradas para duas economias. Para uma discussão mais detalhada do conceito de hiato tecnológico e das questões relativas a mensuração veja-se, entre outros, FAGERBERG (1988). 
Desde que tomemos como hipótese a existência de hiato inicial e que assumamos que $\mu>\rho$, o modelo, assim como proposto por Fagerberg (1988), apresentará sistematicamente a manutenção de um hiato tecnológico entre as economias desenvolvidas e em desenvolvimento, dado por $H^{*}=\mu /(\mu-\rho)$. Finalmente, a equação (2) permite verificar que quanto maior a taxa de progresso técnico dos países desenvolvidos e menor o esforço tecnológico dos países emergentes, maior será o diferencial tecnológico de equilíbrio entre os dois blocos de países.

Esta apresentação formal é representativa das referências teóricas adotadas pelo trabalho, tanto em sua versão cepalina quanto evolucionista, dado que apresenta como resultado central a ocorrência de trajetórias tecnológicas divergentes entre as economias desenvolvidas e em desenvolvimento.

\subsubsection{Comportamento das Transações de Natureza Comercial e Demanda por Ativos Externos}

O objetivo desta subseção é definir o comportamento das transações comerciais do grupo de economias em desenvolvimento ante os países desenvolvidos. Para tanto, torna-se necessário definir explicitamente os elementos determinantes do comportamento de suas exportações e importações. ${ }^{5}$

Utiliza-se como referência teórica básica para esta definição o modelo desenvolvido por McCombie e Thirwall (1994), ao qual se incorpora o papel exercido pela competitividade externa via qualidade derivada do desenvolvimento e difusão do progresso tecnológico, tal como expresso pelas equações (3) e (4) abaixo:

$$
\frac{d x}{d t}=a 1\left(\frac{d p}{d t}-\frac{d p^{*}}{d t}\right)+b 1 \log \left(\frac{T e}{T d}\right)+\varepsilon \frac{d z}{d t}
$$

5 Assume-se, por hipótese, que o resultado do saldo em transações correntes será igual ao saldo comercial. De outra forma, supomos, como condição inicial e simplificadora, a vigência de equilíbrio na conta de serviços e transferências unilaterais. Esta é uma simplificação do modelo que tem seu foco no comportamento das transaçôes de natureza comercial. Não obstante, conforme será discutido na última seção do trabalho, esta simplificação não altera significativamente os resultados. Pelo contrário, a incorporação destas contas, dado seu comportamento na América Latina, apenas reforça estes resultados. 


$$
\frac{d m}{d t}=a 2\left(\frac{d p^{*}}{d t}-\frac{d p}{d}\right)+b 2 \log \left(\frac{T d}{T e}\right)+\pi \frac{d y}{d t}
$$

Onde: $d x / d t$ é a variação temporal das exportações; $d m / d t$ é a variação temporal das importações; $d p / d t$ é a variação temporal dos preços internos; $d p^{*} / d t$ é a variação temporal dos preços externos; $T_{e}$ é o nível tecnológico nas economias em desenvolvimento; $T_{d}$ é o nível tecnológico nas economias desenvolvidas; $d z / d t$ é a taxa de mudança da renda real mundial; $d y / d t$ é a taxa de mudança do produto da economia do Sul; $\varepsilon$ e $\pi$ são os coeficientes positivos de ajustamento às variações na renda, das exportações e das importações, respectivamente; $a_{1}, a_{2}$ são os coeficientes negativos que medem o impacto da variação dos preços externos e internos sobre as exportações e importações, respectivamente; $b_{1}, b_{2}$ são os parâmetros positivos que medem o impacto do hiato tecnológico sobre as exportações e importações.

As equações (3) e (4) mostram que as exportaçôes das economias em desenvolvimento dependem: 1) de sua competitividade-preço, medida pela diferença em relação ao nível de preços das economias desenvolvidas; 2) do tamanho do hiato tecnológico em relação às economias desenvolvidas; e 3) da taxa de mudança das economias desenvolvidas, ponderada pelos coeficientes relevantes em cada caso. No mesmo sentido, as importações das economias em desenvolvimento dependem: 1) de sua competitividade-preço; 2) do tamanho do hiato tecnológico; e 3 ) de sua taxa de variação da renda ponderada pelo coeficiente da renda.

Trata-se, portanto, como afirmado inicialmente, de uma versão da abordagem McCombie e Thirlwall (1994) à qual se incorpora o papel desempenhado pelo nível de progresso tecnológico. A justificativa para a incorporação desta variável no comportamento das transações comerciais é derivada de seu papel fundamental na definição da capacidade de competição em qualidade de produtos. Sua referência na literatura é encontrada, entre outros, em trabalhos tais como Fagerberg (1988) e Verspagen (1994).

O objetivo é adicionar ao modelo básico McCombie e Thirlwall (1994), no qual o comportamento da balança comercial é definido pelos coeficientes de 
resposta a preços e rendas de importações e exportações, o fator "qualidade”, cujo desenvolvimento apresenta-se vinculado ao grau de progresso tecnológico.

Na subseção anterior foi adotado um padrão de difusão-incorporação de tecnologia que gera como resultado a existência de um hiato tecnológico para os países em desenvolvimento, o que, em termos do resultado comercial, implica uma tendência sistemática de geração de déficits no saldo em transações correntes.

Se adotarmos a vigência da hipótese fraca da paridade do poder de compra, e lembrarmos que o modelo é construído para o regime de câmbio fixo, então a superação do déficit comercial encontra-se diretamente vinculada ao comportamento relativo das taxas de crescimento interno e do resto do mundo e dos respectivos coeficientes de resposta das mudanças na renda, de importação e exportação, como observado nas equações $\left(3^{\prime}\right)$ e $\left(4^{\prime}\right)$ abaixo:

$$
\begin{aligned}
& \frac{d x}{d t}=b 1 \log \left(\frac{T e}{T d}\right)+\varepsilon \frac{d z}{d t} \\
& \frac{d m}{d t}=b 2 \log \left(\frac{T d}{T e}\right)+\pi \frac{d y}{d t}
\end{aligned}
$$

As equações $\left(3^{\prime}\right)$ e $\left(4^{\prime}\right)$ fornecem um modelo em que o comportamento das transações comercial das economias em desenvolvimento depende - dada a hipótese de paridade do poder de compra - do comportamento da renda interna, da renda externa e do grau relativo de desenvolvimento tecnológico.

Definido o comportamento das transações de natureza comercial para as economias em desenvolvimento, passamos a investigar o comportamento de sua demanda por ativos externos (DAE).

A DAE é entendida neste trabalho como o volume de ativos externos que as economias em desenvolvimento precisam absorver em suas transações financeiras em razão dos desequilíbrios vigentes em suas transações correntes. Desta forma, a DAE é definida como sendo igual ao déficit no saldo em 
transações correntes. ${ }^{6}$ Se utilizarmos a suposição de que o saldo da balança de serviços e de transferências unilateral está equilibrado, então o resultado do saldo em transações correntes é igual ao resultado da balança comercial, e a DAE passa a ser, portanto, a diferença entre importaçóes e exportações das economias em desenvolvimento. Sua variação temporal será descrita pela diferença entre a taxa de variação no tempo das importações e exportações, como apresentado na equação (5).

Onde: $d A^{d} / d t$ é a variação temporal da demanda por ativos externos.

$$
\frac{d A^{d}}{d t}=\frac{d m}{d t}-\frac{d x}{d t}
$$

Substituindo $\left(3^{\prime}\right)$ e $\left(4^{\prime}\right)$ em $(5)$, obtemos $(6)$ :

$$
\frac{d A^{d}}{d t}=b 2 \log \left(\frac{T d}{T e}\right)+\pi \frac{d y}{d t}-b 1 \log \left(\frac{T e}{T d}\right)-\varepsilon \frac{d z}{d t}
$$

A equação (6) pode ser simplificada a partir da adoção de duas hipóteses convencionalmente usadas: 1) que a diferença entre o grau relativo de desenvolvimento tecnológico entre os países desenvolvidos e em desenvolvimento e seu impacto sobre o resultado comercial sejam constantes e 2) que a taxa de mudança do resto do mundo (neste caso, dos países desenvolvidos) seja também constante. Destas simplificaçóes obtemos $\left(6^{\prime}\right)$, como apresentado abaixo:

$$
\frac{d A^{d}}{d t}=H+\pi \frac{d y}{d t}
$$

Onde $H^{\prime}: H_{s}-Z$

$H_{s}: b_{2}\left(\log T_{d} / T_{e}\right)-b_{1}\left(\log T_{d} / T_{d}\right)$, que representa o papel do grau de desenvolvimento tecnológico sobre o resultado comercial.

$Z$ : constante

6 Pela definição, torna-se claro que a ocorrência de um superávit no saldo em transações correntes gera uma DAE negativa.

Est. econ., São Paulo, 34(3): 515-551, jul-set 2004 
A equação $\left(6^{\prime}\right)$ informa que a taxa de mudança da demanda por ativos externos é uma função da taxa de mudança da renda interna ponderada pelo coeficiente de importação, e do montante de demanda por ativos, fruto do hiato tecnológico, indicado pela constante $H^{\prime}$.

Neste momento adotaremos a hipótese, amplamente considerada na macroeconomia de inspiração keynesiana e kaleckiana, de que a taxa de variação da renda interna é determinada pelo comportamento da demanda agregada da economia, mais especificamente pela taxa de mudança da demanda por investimentos do sistema, e que esta última, seguindo especificamente a tradição keynesiana, é uma função da taxa de juros vigente, tal como descrito pelas equações $(7)$ e $(8):^{7}$

$$
\begin{aligned}
& \frac{d y}{d t}=\frac{d I}{d t} \\
& \frac{d I}{d t}=-\delta i
\end{aligned}
$$

Onde: $d I / d t$ é a taxa de mudança dos investimentos; $i$ é taxa de juros e $\delta$ é a sensibilidade-juros da demanda por investimentos.

$$
\frac{d A^{d}}{d t}=H^{\prime}-\phi i
$$

Substituindo (7) e (8) em 6' obtemos (9):

Onde: $\phi: \pi \delta$

\section{Graficamente teremos, portanto:}

7 Associar a taxa de crescimento de uma economia à taxa de crescimento do investimento é uma simplificação. Não obstante, esta limitação nos parece justificável em duas dimensões. Em primeiro lugar, o artigo não tem como objetivo discutir a dinâmica do crescimento econômico. Seu foco é mais limitado. Incorporar um modelo teórico mais complexo sobre os determinantes do crescimento implicaria uma elevação da complexidade do modelo e tornaria obscuro o foco do trabalho. A simplicidade parece justificável em razão dos objetivos do trabalho. Em segundo lugar, conforme explícito no texto, este tipo de compreensão, ainda que limitada eminentemente a uma dinâmica de curto prazo, é o elemento básico de toda a tradição em macroeconomia de inspiração keynesiana e kaleckiana, na qual a taxa de crescimento do produto da economia é determinada pelo comportamento da demanda agregada, em especial do componente de investimento. 
FIGURA 1 - DEMANDA POR ATIVOS EXTERNOS E TAXA DE JUROS

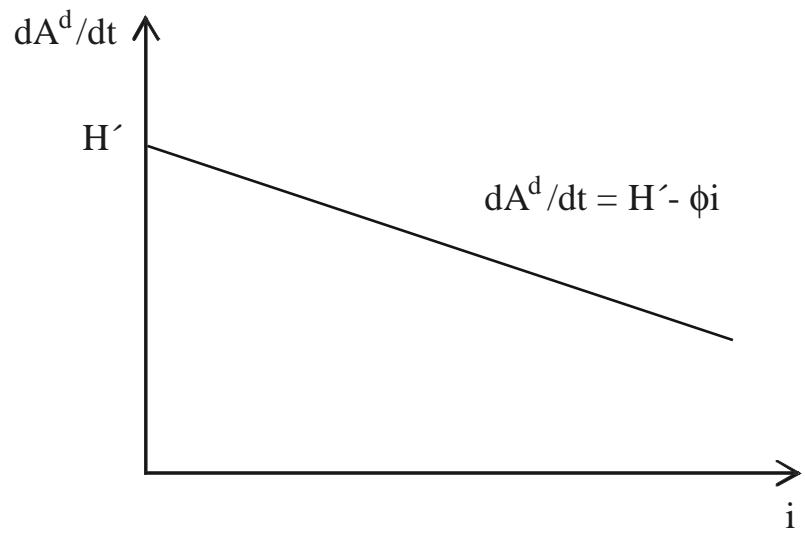

O intercepto da curva de demanda por ativos externos é representado pelo volume de demanda por ativos derivado do hiato tecnológico $\left(H^{\prime}\right)$, enquanto a inclinação da curva é estabelecida pelo parâmetro $\phi$.

A configuração da demanda por ativos externos foi, portanto, derivada das condições inicialmente estabelecidas para o comportamento das transações de natureza comercial das economias em desenvolvimento. Sua configuração final indica a existência de uma relação inversa entre seu crescimento e o comportamento da taxa de juros. A explicação para este resultado encontrase, em última instância, no vínculo entre taxa de juros e o crescimento interno e deste último com o comportamento da demanda por bens importados.

Estabelecidos estes pontos, vejamos na seqüência o modelo de alocação de portfólio, ou seja, o lado financeiro do modelo.

\subsection{Alocação de Portfólio num Contexto de Restrição da Oferta de Capital}

Nesta parte do trabalho será abordado o comportamento dos fluxos de capital de curto prazo entre economias em desenvolvimento e desenvolvidas e suas relações com o resultado obtido no "lado real" do balanço de pagamentos. Esta tarefa é realizada a partir da construção de um modelo de alocação de portfólio no qual os movimentos de capital se dão unilateralmente das economias desenvolvidas para as economias em desenvolvimento. 
No modelo, os agentes nas economias em desenvolvimento mantêm, inicialmente, sua riqueza sob a forma de moeda local $\left(M_{e}\right)$ e títulos locais $\left(A_{e}\right)$ a partir do cálculo comparativo entre suas necessidades de liquidez e o rendimento ofertado pelos títulos.

Já os agentes das economias desenvolvidas têm à sua disposição três formas de alocação de sua riqueza: moeda local $\left(M_{d}\right)$, títulos locais $\left(A_{d}\right)$ e títulos das economias em desenvolvimento $\left(A_{e}\right)$. O total de riqueza financeira das economias desenvolvidas $(W)$ é igual à soma de $M_{d}, A_{d} \mathrm{e} A_{e}$.

Da mesma forma que nas economias em desenvolvimento, os agentes decidem sua alocação entre moeda local e títulos a partir do cálculo comparativo entre suas necessidades de liquidez e o rendimento ofertado pelos títulos. A diferença, neste caso, é que os agentes das economias desenvolvidas têm a possibilidade de aplicar uma parcela de sua riqueza em títulos das economias em desenvolvimento, em razão do cálculo comparativo entre risco/retorno destes ativos.

Inicialmente, imaginemos que a escolha entre $A_{d}$ e $A_{e}$ seja procedida apenas em função do diferencial de retornos entre os ativos, sem levar em consideração o fator risco.

A crescente necessidade de recursos financeiros externos que caracteriza as economias em desenvolvimento num contexto de "rigidez" de ajuste comercial - derivada do hiato tecnológico - imprime, como condição necessária e suficiente para seu ajuste externo, a execução de políticas monetárias restritivas que mantenham um diferencial de retorno positivo para os agentes das economias desenvolvidas.

Neste contexto, não haveria, desde que fosse mantido o diferencial de juros positivo de seus ativos vis-à-vis aos ativos ofertados nas economias desenvolvidas, qualquer restrição externa às economias em desenvolvimento. Esta é uma abordagem muito simplificada e que não capta alguns fatos estilizados de suma importância no cenário financeiro internacional. Em especial, como sugerido na seção anterior, nas recentes crises cambiais, a promoção de contínuas elevações nas taxas de juros das economias em desenvolvimento - 
mesmo num contexto de estabilidade das taxas de juros internacionais - foi incapaz de conter os ataques especulativos a estas moedas.

Esta incapacidade da taxa de juros em adequar as entradas e saídas de ativos das economias em desenvolvimento, ou seja, em impedir a ocorrência das crises cambiais reflete, em última instância, o fato de que as taxas de juros não desempenharam de modo satisfatório seu papel enquanto mecanismo regulador de mercado. Esta incapacidade em ajustar os movimentos de entrada e saída de ativos externos pode ser entendida - entre outras explicações - como fruto da existência de um problema de "racionamento" dos fluxos de ativos externos para estas economias. O conceito de racionamento, em especial o racionamento de crédito, se constitui numa importante área de estudo da macroeconomia novo-keynesiana.

Stiglitz e Weiss (1981) estabeleceram as bases para estes estudos. Os autores demonstraram que, num ambiente caracterizado pela distribuição assimétrica de informações, o retorno esperado dos empréstimos exibe uma relação não-linear com as taxas de juros, já que elevações nestas taxas tendem a gerar problemas de seleção adversa - tomadores de qualidade podem deixar de tomar o empréstimo, dada a incapacidade de pagamento, enquanto os tomadores de menor qualidade podem sentir-se estimulados a tomar empréstimos - e de perigo moral, já que a elevação da taxa de juros, ao reduzir a rentabilidade dos investimentos, estimula os tomadores a realizarem empreendimentos de maior risco, com reduzida probabilidade de sucesso.

Seguindo este raciocínio, os autores estabelecem a existência de uma taxa de juros $\left(i_{\max }\right)$ que maximiza o retorno esperado dos empréstimos. Mesmo que o tomador esteja disposto a pagar uma taxa superior, os efeitos de seleção adversa e perigo moral geram, a partir deste ponto, uma queda do retorno esperado. A decisão do banco, a partir deste ponto, é não emprestar. A taxa de juros passa, portanto, a não exercer seu papel de equalizador entre oferta e demanda por crédito, ou seja, o racionamento de crédito passa a vigorar.

A incapacidade da taxa de juros em adaptar entradas e saídas de ativos externos nas recentes crises cambiais pode ser explicada de forma análoga. A elevação da taxa de juros - num contexto de assimetria de informaçóes - 
geraria os problemas de seleção adversa - os "bons tomadores" não aceitariam pagar as taxas de juros pagas por outras economias para atrair capital, ficando fora, portanto, deste circuito - e de perigo moral - as elevadas taxas de juros induziriam a realização de investimentos com risco elevado nos países em desenvolvimento. ${ }^{8}$

Neste contexto, a capacidade da taxa de juros enquanto mecanismos equalizador entre oferta e demanda por ativos externos é limitada. Isto se justifica pelo comportamento do retorno esperado dos investimentos em relação à taxa de juros. Assim como proposto por Stiglitz e Weiss (1981), haveria uma taxa de juros que maximizaria o retorno esperado destes investimentos. Acima desta taxa o retorno esperado tenderia a reduzir-se, o que provocaria uma redução na oferta de ativos externos das economias desenvolvidas para as economias em desenvolvimento.

\subsubsection{Demanda por Ativos Externos num Contexto de Restrição da Oferta}

A equação (10) explicita formalmente a hipótese de restrição da oferta de ativos externos dos países desenvolvidos em ativos das economias em desenvolvimento. A idéia essencial é que existe uma taxa de juros $\left(i_{\max }\right)$ que maximiza o retorno esperado dos agentes. A partir desta taxa - em razão dos problemas de seleção adversa e risco moral, característicos de um ambiente com distribuição assimétrica de informações - este retorno esperado tende a ser decrescente, o que explica a redução dos investimentos nas economias em desenvolvimento.

$$
\frac{d A^{s}}{d t}=f(i)=\alpha i-\beta i^{2}
$$

8 Há ainda um outro elemento, destacado com maior freqüência pela literatura de inspiração minskyana, que se refere aos efeitos dos fluxos sobre os estoques. As entradas de ativos das economias desenvolvidas para compra de títulos das economias emergentes têm como contrapartida a elevação da dívida destas economias. Para um período de estabilidade no crescimento estaríamos, portanto, verificando a elevação da relação dívida/PIB, o que poderia ser entendido pelos agentes como uma elevação da vulnerabilidade externa das economias emergentes. 
Onde:

$d A^{s} / d t=$ taxa de mudança da oferta de ativos das economias desenvolvidas para as economias em desenvolvimento

$i=$ taxa de juros das economias em desenvolvimento

$\alpha, \beta=$ parâmetros positivos.

Deve-se observar que essa equação implica um comportamento dos agentes similar ao previsto pela equação da paridade não coberta de juros (UIP), isto é, o aumento da taxa de juros interna atrai mais capital para a economia nacional. Todavia, à diferença da UIP, a equação (10) supõe que juro e risco não são variáveis independentes, e que o aumento da taxa de juros implica a conseqüente elevação do risco, o que explica a queda da taxa de mudança da oferta de financiamento para valores altos da taxa de juros. Este é, precisamente, o objetivo de incluir uma não-linearidade na curva da taxa de mudança da oferta e financiamento - levar em conta esse duplo efeito dos juros: um efeito favorável via aumento da taxa de retorno, e o outro desfavorável, via aumento do risco. ${ }^{9}$ O entendimento do comportamento desta equação é substancialmente facilitado por sua exposição gráfica, como se segue:

9 O aumento dos juros internos poderia deprimir a entrada de capitais via aumento das expectativas de desvalorização cambial, à medida que juros extremamente altos não sejam percebidos como sustentáveis pelos agentes. Essa possibilidade não afetaria significativamente a funcionalidade da equação (10). Todavia, com o intuito de não abrir mais uma frente de análise, o artigo supõe expectativas estáticas de desvalorização - mais especificamente, supõe que os agentes acreditam que não mudará o regime cambial e que a taxa de juros e o produto são os únicos mecanismos de ajustamento da economia. 
FIGURA 2 -OFERTA DE ATIVOS EXTERNOS E TAXA DEJUROS

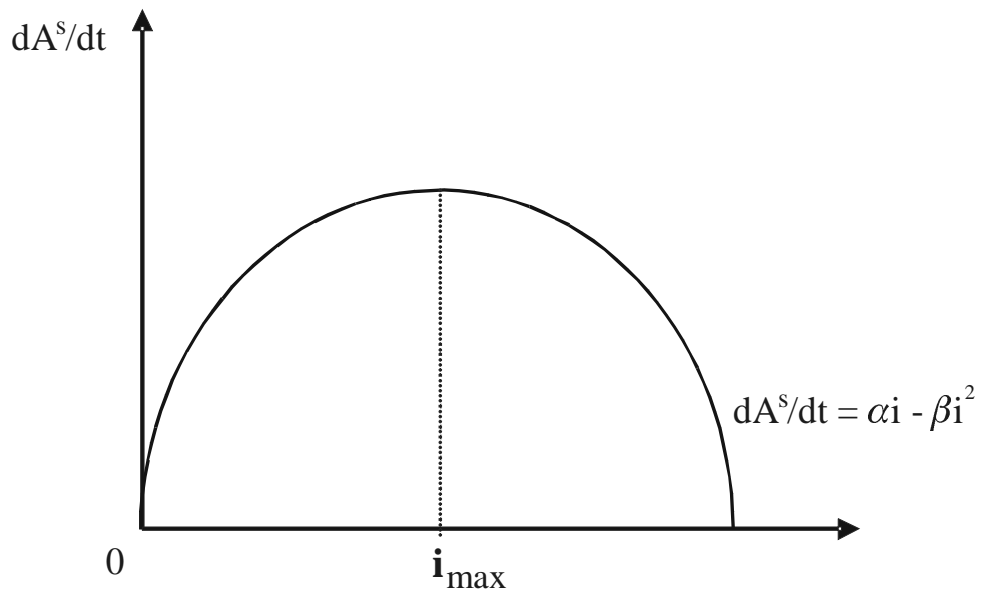

O ponto $i_{\text {max }}$ indica a taxa de juros que maximiza o retorno esperado dos investimentos (a oferta de ativos externos) das economias desenvolvidas para as economias em desenvolvimento. Esta formatação é bastante interessante por sua simplicidade e por permitir a expressão da hipótese central do modelo, de que num ambiente com assimetria de informações existirá uma taxa de juros que maximiza o retorno esperado dos investimentos dos países desenvolvidos e que, portanto, representa a taxa máxima de investimentos. ${ }^{10}$

\subsection{Oferta e Demanda por Ativos Externos}

Nesta subseção combinaremos o modelo desenvolvido acima com a função de demanda por ativos externos.

Em equilíbrio, quando a oferta de ativos igualar a sua demanda, ou seja, $d A^{s} / d t$ $=d A^{d} / d t$, teremos: $\alpha i-\beta i^{2}=H^{\prime}-\phi i$, mostrando a possibilidade - sob certas condições - de existência de duas soluções de equilíbrio para a taxa de juros, como será demonstrado na próxima subseção.

Adotaremos como hipótese que a fixação da taxa de juros nas economias emergentes é função exclusiva do Banco Central. Dada a característica de demandante estrutural por ativos externos, a política dos Bancos Centrais destas economias irá utilizar a taxa de juros como um mecanismo de atração

10 Como hipótese adicional admitimos que, neste momento, a expectativa de desvalorização cambial é nula. 
de capitais com o objetivo explícito de permitir o equilíbrio entre oferta e demanda por ativos externos.

$$
\frac{d i}{d t}=\lambda\left(\frac{d A^{d}}{d t}-\frac{d A^{s}}{d t}\right)
$$

Desta forma, a taxa de juros estará subindo sempre que a taxa de mudança da demanda por ativos externos for superior à taxa de mudança da oferta de ativos externos. Caso contrário, esta taxa estará se reduzindo. Apresentamos, portanto, o seguinte sistema:

$$
\left\{\begin{array}{l}
\frac{d A^{d}}{d t}=H^{\prime}-\phi i \\
\frac{d A^{s}}{d t}=\alpha i-\beta i^{2} \\
\frac{d i}{d t}=\lambda\left(\frac{d A^{d}}{d t}-\frac{d A^{s}}{d t}\right)
\end{array}\right.
$$

Vejamos, graficamente, o equilíbrio conjunto entre oferta e demanda por ativos externos e o movimento da taxa de juros, tal como descrito no modelo.

FIGURA 3 - OFERTA E DEMANDA POR ATIVOS EXTERNOS E OS EQUILÍBRIOS MÚLTIPLOS DAS TAXAS DEJUROS

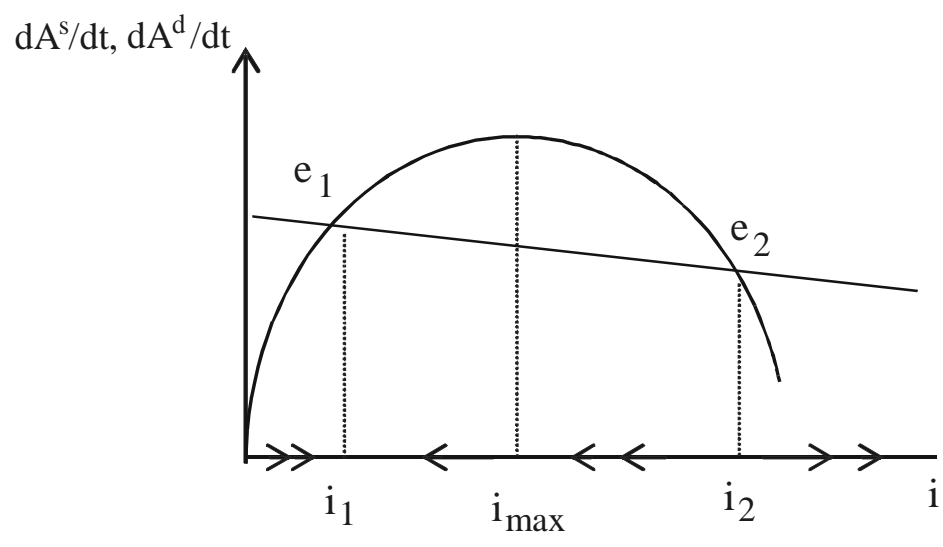

Est. econ., São Paulo, 34(3): 515-551, jul-set 2004 
O sistema apresenta, portanto, duas soluções de equilíbrio $e_{1}$ e $e_{2}$, para os quais $d A^{s} / d t=d A^{d} / d t$ e portanto $d i / d t=0$. A questão a ser discutida é se as soluçôes de equilíbrio - taxas de juros $i_{1}$ e $i_{2}$ - são equilíbrios estáveis. Precisamos, portanto, analisar qual o movimento de $d i / d t$ em pontos na vizinhança a $i_{1}$ e $i_{2}$. Vejamos, primeiro, o caso de $i_{1}$. Pontos à esquerda de $i_{1}$ apresentam $d A^{d} / d t>d A^{s} / d t$ e, portanto, $d i / d t>0$. Pontos à direita de $i_{1}$ apresentam $d A^{d} / d t<d A^{s} / d t$ e, portanto, $d i / d t<0$. O ponto $i_{1}$ é um equilíbrio estável (um atrator) tendo em vista que pontos na sua vizinhança conduzem necessariamente a um retorno para $i_{1}$

Vejamos o caso da taxa de juros $i_{2}$. Pontos à esquerda de $i_{2}$ apresentam $d A^{s}$ / $d t>d A^{d} / d t$ e, portanto, $d i / d t<0$. Pontos à direita de $i_{2}$ apresentam $d A^{s} / d t$ $<d A^{d} / d t$ e, portanto, $d i / d t>0$. O ponto $i_{2}$ é um equilíbrio instável (um repulsor), já que pontos na sua vizinhança conduzem necessariamente a uma trajetória que se afasta continuamente deste equilíbrio.

\subsubsection{Oferta e Demanda por Ativos Externos e o Comportamento das Reservas}

As reservas cambiais do Banco Central dos países emergentes são constituídas pela entrada de ativos externos, expressa pela equação (10) de oferta de ativos externos dos países desenvolvidos para os emergentes, descontada a saída de ativos do Bacen, representada pela equação (9) de demanda por ativos externos. A taxa de mudança das reservas será, portanto, expressa por:

$$
\frac{d r}{d t}=\frac{d A^{s}}{d t}-\frac{d A^{d}}{d t}
$$

Como $d A^{s} / d t$ e $d A^{d} / d t$ são uma função da taxa de juros da economia, logo o comportamento das reservas será definido, em última instância, pelo comportamento da taxa de juros. Precisamos, portanto, analisar qual o comportamento das reservas para os equilíbrios definidos em $i_{1}$ e $i_{2}$, o que é realizado a partir da análise gráfica a seguir. 
FIGURA 4 - EQUILÍBRIOS MÚLTIPLOS DA TAXA DE JUROS E O COMPORTAMENTO DAS RESERVAS

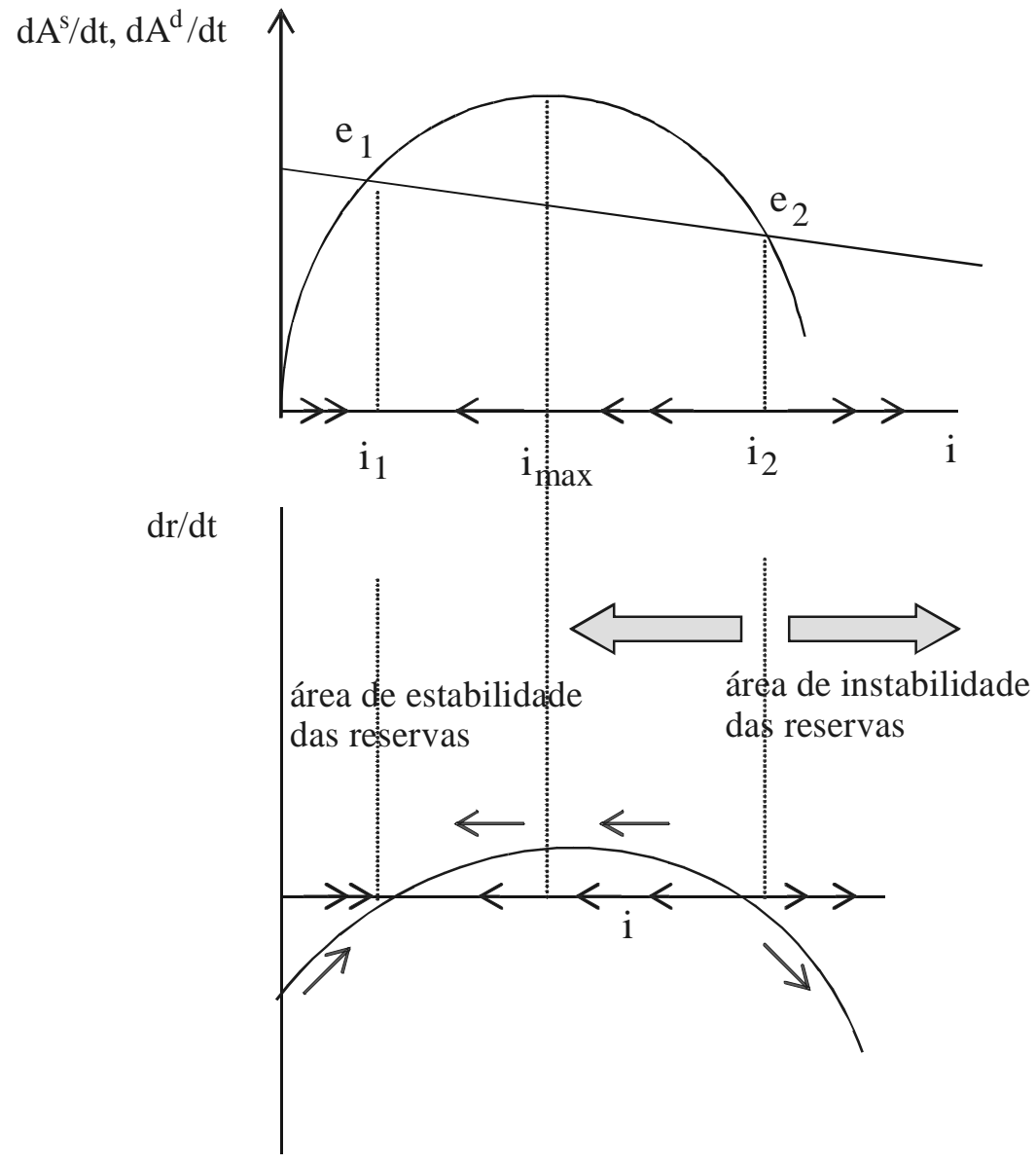

Em $i_{1}$ e $i_{2}, d A^{s} / d t=d A^{d} / d t$ e, portanto, $d i / d t=0$, onde $d r / d t=0$. Vejamos o que acontece quando o sistema se apresenta em ponto na vizinhança de $i_{1} \mathrm{e}$ $i_{2}$. Em pontos à esquerda de $i_{1}, d A^{d} / d t>d A^{s} / d t$, o que provoca o movimento de elevação nas taxas de juros $(d i / d t>0)$. Enquanto o desequilíbrio persistir, as taxas de juros se manterão crescente, o que implicará, neste momento, uma elevação em $d A^{s} / d t$ e numa redução em $d A^{d} / d t$. Há uma tendência, em razão do funcionamento do mecanismo de ajuste da taxa de juros, de que o desequilíbrio seja eliminado, ou seja, que $d r / d t$ tenda a zero. Em pontos à direita de $i_{1}, d A^{s} / d t>d A^{d} / d t$, o que provoca o movimento de redução nas taxas de juros $(d i / d t<0)$. Enquanto o desequilíbrio persistir, as taxas 
de juros permanecerão caindo. Há, portanto, uma tendência, em razão do funcionamento do mecanismo de ajuste da taxa de juros, de que o desequilíbrio seja eliminado, ou seja, $d r / d t=0$. Vejamos agora o caso do equilíbrio em $i_{2}$. Em pontos à esquerda de $i_{2}, d A^{s} / d t>d A^{d} / d t$, o que provoca o movimento de redução nas taxas de juros até que $i_{1}$ seja alcançado. O raciocínio análogo ao desenvolvido acima determina que $d r / d t$ tenderá ao equilíbrio.

O ponto mais relevante, no entanto, é analisar o comportamento de pontos à direita de $i_{2}$. Neste caso, teremos $d A^{d} / d t>d A^{s} / d t$, o que provocará a explosão da taxa de juros (para pontos à direita de $i_{2}, d i / d t>0$ ). No entanto, apesar da elevação da taxa de juros, a oferta de capital encontra-se, neste ponto, em sua fase decrescente, dado que $i_{2}>i_{\max }$. A ampliação da taxa de juros é incapaz de ajustar o desequilíbrio entre oferta e demanda, o que implica uma tendência a $d r / d t<0$.

Tal como exposto, a taxa de juros exerce sua função de equalizadora entre os movimentos de oferta e demanda de ativos externos até o ponto em que $i=$ $i_{\text {max }}$. A partir deste ponto - em razão dos problemas de seleção adversa e risco moral - o retorno esperado dos investimentos passa ser decrescente. Este ponto evidencia a razão pela qual as políticas de elevação nas taxas de juros são incapazes - a partir de certos patamares - de ajustar os movimentos entre oferta e demanda por ativos, elemento verificado nas recentes experiências concretas de combate à fuga de capitais.

\subsubsection{Déficit Estrutural, Regime Cambial e Ataque Especulativo}

Nesta subseção analisaremos o impacto de uma elevação no déficit estrutural do balanço de pagamentos, representado, em nosso modelo, pelo componente estrutural de demanda por ativos externos associado ao hiato tecnológico $\left(H^{\prime}\right)$. A incorporação desta discussão num ambiente caracterizado pela distribuição assimétrica de informações e por uma política de fixação da taxa de câmbio pelo Banco Central é um componente fundamental no entendimento da geração dos ataques especulativos às moedas das economias em desenvolvimento. 
A elevação do hiato tecnológico e, portanto, da demanda por ativos externos, implicará um deslocamento para cima da curva de demanda por ativos, como demonstrado a seguir.

FIGURA 5 - AMPLIAÇÃO DO HIATO E SEU IMPACTO SOBRE A ÁREA DE ESTABILIDADE DAS RESERVAS

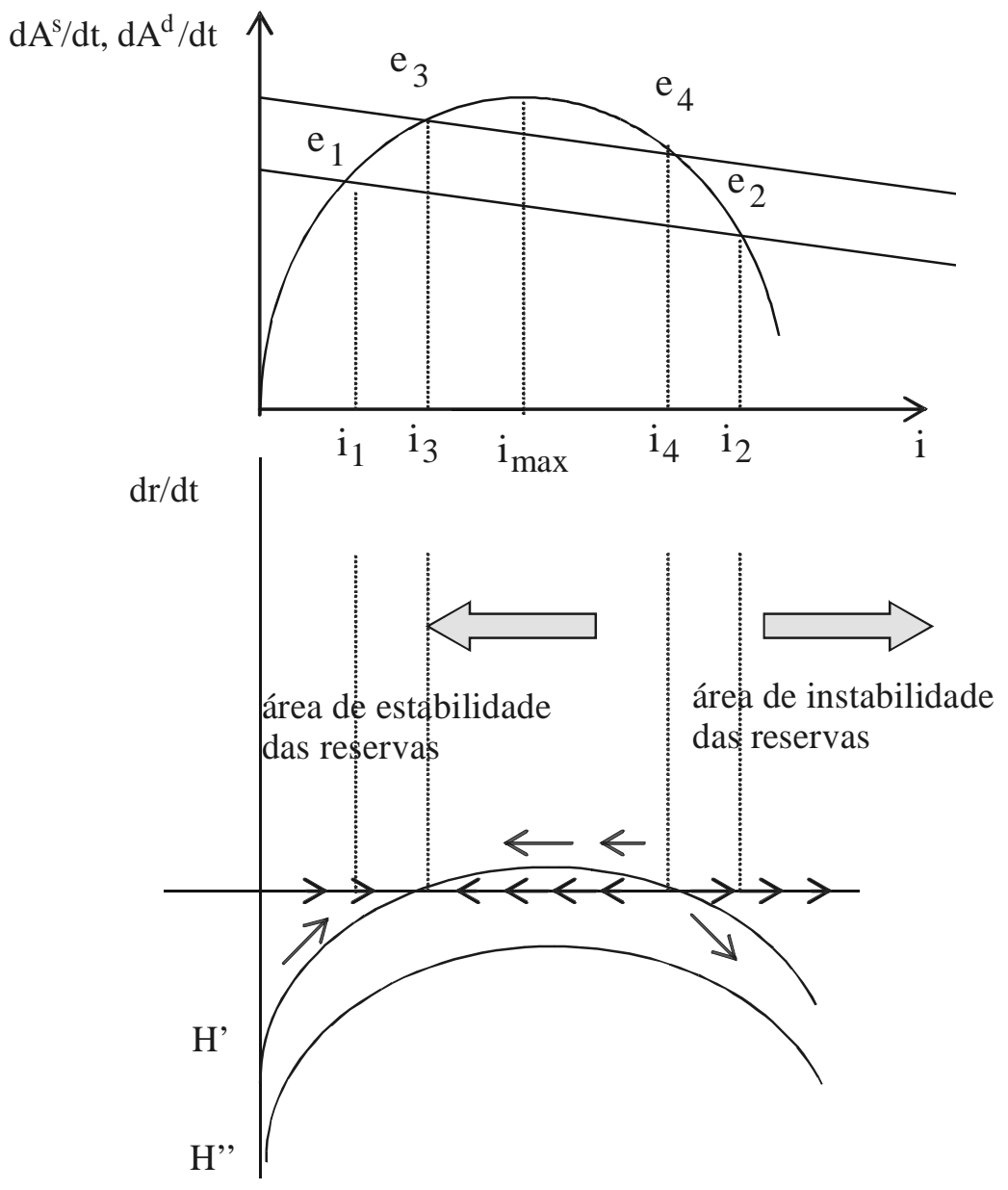

Os equilíbrios iniciais indicados por $i_{1}$ e $i_{2}$ são substituídos agora por $i_{3} \mathrm{e} i_{4}$. O resultado fundamental que é observado graficamente é que a área de estabilidade das reservas é reduzida em razão da ampliação do componente estrutural do déficit no balanço de pagamentos associado ao hiato tecnológico $\left(H^{*}\right)$. Ampliações no componente estrutural do déficit no balanço de pagamentos que implicam uma crescente demanda por ativos externos se consti- 
tuem - num contexto de restrição da oferta de ativos - num componentechave para a explicação da instabilidade no nível de reservas.

Este problema se torna mais grave quando o Banco Central do país em desenvolvimento resolve adotar uma política de controle sobre a taxa de câmbio, tal como o ocorrido no Brasil entre 1994 e 1998 e no México no início dos anos 90. A fixação da taxa de câmbio, condição necessária para a ocorrência de um ataque especulativo, ${ }^{11}$ combinada com as condições de restrição da oferta de ativos externos e de demanda crônica por ativos torna insustentável o regime cambial.

A credibilidade dos agentes privados em relação à manutenção da paridade cambial será considerada uma função das expectativas dos agentes sobre o comportamento futuro das reservas do Banco Central. Aos agentes privados caberá - sempre que a credibilidade no regime cambial for abalada - realizar operações de hedge cambial a partir da compra de moeda estrangeira no mercado, o que se constitui numa fonte adicional de demanda por ativos externos, cujo comportamento independe do nível de renda da economia e do hiato tecnológico.

Finalmente, resta adicionar uma nova hipótese ao modelo, qual seja, que há assimetria na distribuição de informações entre o Banco Central e os agentes privados.

No modelo, o Banco Central possui todas as informações relevantes sobre o comportamento dos estoques de ativos externos. Já os agentes privados não possuem tais informações, o que os impede de determinar com absoluta segurança o comportamento das reservas.

Desta forma, sempre que as reservas forem reduzidas, os agentes privados não serão capazes de analisar se esta redução conduz a um nível de equilíbrio com um nível de reservas menor e a manutenção da paridade cambial é

11 A ocorrência de ataques especulativos é restrita aos regimes nos quais o Banco Central predetermina a taxa de câmbio, tal como o regime de câmbio fixo ou a banda cambial. Num regime de câmbio flutuante, os excessos de oferta e demanda são eliminados por meio do funcionamento dos mecanismos de mercado, vale dizer, por meio das flutuações da taxa de câmbio. 
crível, ou se esta redução irá conduzir o sistema para uma eliminação total das reservas e, portanto, a manutenção da paridade cambial fixa é não-crível.

A elevação do déficit estrutural no balanço de pagamentos e a conseqüente ampliação da área de instabilidade das reservas irão gerar - neste contexto de assimetria de informações e dado que os agentes são considerados avessos ao risco - uma elevação na demanda por ativos externos para proteção contra futuras alteraçốes na paridade cambial. À medida que a demanda por ativos para operaçóes de hedge se amplie - provocando novos deslocamentos para cima na curva de demanda por ativos - é também ampliada a área de instabilidade das reservas, até o ponto em que a geração do ataque especulativo seja inevitável.

Formalmente, substituindo na equação (12) a demanda e oferta de ativos pelas equações (9) e (10), respectivamente, tem-se que $d r / d t=(\alpha+\phi) i-b i^{2-} H^{\prime}$. Essa equação permite observar que se o hiato tecnológico é muito grande i.e. se os problemas de competitividade estrutural da economia periférica são muito importantes - não existe nenhuma taxa de juros que possa estabilizar suas reservas, inviabilizando a política de taxa de câmbio fixa. Este resultado pode ser facilmente compreendido a partir da observação da Figura 5. Uma ampliação do hiato tecnológico, tal como o deslocamento de $H^{\prime}$ para $H^{\prime}$ pode gerar uma situação na qual não existam equilíbrios para a taxa de juros.

Dois pontos devem ser destacados. Em primeiro lugar, o ataque especulativo ocorrerá tanto mais rapidamente quanto maior for a proporção dos agentes privados que entendam que a redução inicial das reservas irá conduzir à sua eliminação total e, portanto, a sustentação do regime cambial não é crível. De outra forma, quanto maior a proporção de agentes que acreditam que a redução das reservas conduz a um nível menor, porém estável, de ativos, mais tempo irá decorrer até que o ataque especulativo ocorra. Em segundo lugar, o ataque especulativo é uma decisão racional dos agentes num contexto de assimetria de informações, tendo em vista que ao antecipar que o regime cambial é insustentável no longo prazo, torna-se vantajoso para os agentes elevar abruptamente sua demanda por ativos, ao invés de realizá-la de modo gradual, o que se justifica, em última instância, tal como 
nos modelos de "primeira geração", em razão dos ganhos que os agentes têm com a antecipação do colapso do regime cambial.

\section{CONSIDERAÇÕES FINAIS}

Em suma, nossa proposta é que a compreensão das recentes crises cambiais na América Latina deve incorporar - além das questões relativas à gestão da política macroeconômica, em especial cambial, e das condições vigentes no sistema financeiro - elementos da inserção internacional da região, em especial sua reduzida capacidade de geração de tecnologia e, fruto desta, sua reduzida competitividade internacional que, concretamente, se traduz na geração de sistemáticos desequilíbrios nas transações correntes e na necessidade de absorção de capitais externos num contexto internacional onde os países emergentes não podem contar indefinidamente com esta fonte de recursos para o fechamento do balanço de pagamentos. Ainda mais, o que procuramos demonstrar é que estes elementos geram problemas que não se resumem a "uma restrição externa de longo prazo ao crescimento", mas podem gerar desequilíbrios de curto prazo que concretamente se traduzam num ataque especulativo.

De forma mais específica, o modelo demonstra a incompatibilidade da fixação da taxa de câmbio em economias que apresentem crônicos déficits em transações correntes e tenham uma capacidade limitada de atração de capitais. A utilização em países da América Latina, tais como o Brasil e o México, de regimes de controle da taxa de câmbio, tal como o regime de bandas cambiais, com intuito de ajudar no processo de combate à inflação, mostrou-se insustentável no tempo. Em alguma medida esta insustentabilidade está vinculada ao comportamento do "lado real" da economia, em específico o baixo grau de desenvolvimento tecnológico em relação aos países desenvolvidos e a conseqüente reduzida competitividade externa destas economias.

Por fim, o modelo permite argumentar que a utilização de regimes de administração de câmbio com valorização dos padrões monetários locais em economias que apresentem as características estilizadas neste trabalho tende a gerar problemas de sustentação da política macroeconômica, em especial da 
variável taxa de câmbio. Em suma, a combinação de reduzido grau de desenvolvimento tecnológico, baixa competitividade externa, capacidade limitada de atração de capitais e valorização da taxa de câmbio apresenta-se insustentável no tempo.

\section{BIBLIOGRAFIA}

CALVO, G.; MENDOZA, E. G. Rational contagion and the globalization of securities markets, Disponível em: < http: // www.imf.org > Acesso em: 11 dez. 1998.

CANUTO, O. Mobilidade de capital e equilíbrio de portfólio. Economia \& Sociedade, Campinas, n. 9, p. 1-47, dez. 1997.

. Fluxos de capital, crise e recuperação na Coréia. Seminário sobre a Coréia. Hotel Le Meridien, Rio de Janeiro, outubro 2000.

CHANG, R.; VELASCO, A. Financial crises in emerging markets: a canonical model. National Bureau of Economic Research Working Papers. n. 6606, june 1998. Disponível em: < http:// www.nber.org > Acesso em: 13 set. 1999.

CORSETTI, G.; PESENTI, P.; ROUBINI, N. What caused the Asian currency and financial crisis. National Bureau of Economic Research Working Papers, n. 6833, december, 1998. Disponível em: < http:// www.nber.org > Acesso em: 13 set. 1999.

FAGERBERG, J. International competitiveness. Economic Journal, Oxford, n. 98, p. 355-374, 1988.

FAJNZYLBER, F. La industrialización trunca de América Latina. México, DF: Editorial Nueva Imagen, 1983.

. Industrialización en América Latina: de la caja negra al casillero vacio. Cuadernos de la Cepal, Santiago, n. 60, 1990.

FLOOD, R.; GARBER, P. M. Collapsing exchange rates regimes: some linear examples. Journal of International Economics, n. 17, p. 1-13, Ago. 1984.

FLOOD, R.; MARION, N. Perspectives on the recent currency crisis literature. National Bureau of Economic Research Working Papers, n. 6380, January 1998. Disponível em: < http://www.nber.org > Acesso em: 21 jan. 1999.

FOLEY, D. K. Financial fragility in developing economies. Discussion Papers, New School of Economics, New York, June 2000.

INTERNATIONAL FINANCIAL STATISTICS. Fundo Monetário Internacional. Diversos números. 
KRUGMAN, P. A model of balance of payment crises. Journal of Money, Credit and Banking, n. 11, p. 311-25, August 1979.

. What happened to Asia? 1998. Disponível em: < http:// www.mit.edu> Acesso em: 14 jun. 1999.

McCOMBIE, J. S. L.; THIRLWALL, A. P. Economic growth and balance of payments constraint. New York: St Martin's Press, 1994.

MINSKY, H. Stabilizing an unstable economy. New Haven: Yale University Press, 1982.

OBSTFELD, M. The logic of currency crises. National Bureau of Economic Reserarch, Working Papers, n. 4640, February 1994. Disponível em: < http: www.nber.org > Acesso em: 14 jun. 1999.

PREBISCH, R. The economic development of Latin America and its principal problems. Document E/CN 12.89, Economic Commission for Latin America, United Nations, 1949.

. La crisis del capitalismo y el comércio internacional. Revista da Cepal, Santiago, n. 20, agosto 1983.

STIGLITZ, J. E.; WEISS. A credit rationing in markets with imperfect information. The American Economic Review, Menasha, v. 71, n. 3, p. 393-416, Jun. 1981.

VERSPAGEN, B. Uneven growth between interdependent economies. Londres: Aldershot, 1993. 
ANEXO I - COMPORTAMENTO DAS RESERVAS INTERNACIONAIS

E DA TAXA DE JUROS EM ECONOMIAS SELECIONADAS

GRÁFICO 3 - COMPORTAMENTO DAS RESERVAS - RÚSSIA

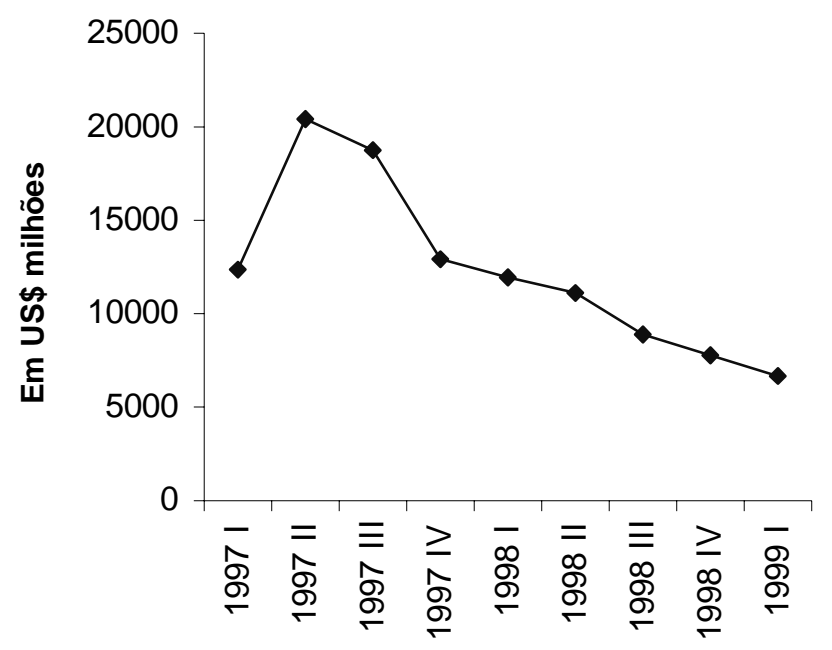

GRÁFICO 4 - TAXA DE JUROS (TAXA DO MERCADO MONETÁRIO RÚSSIA)

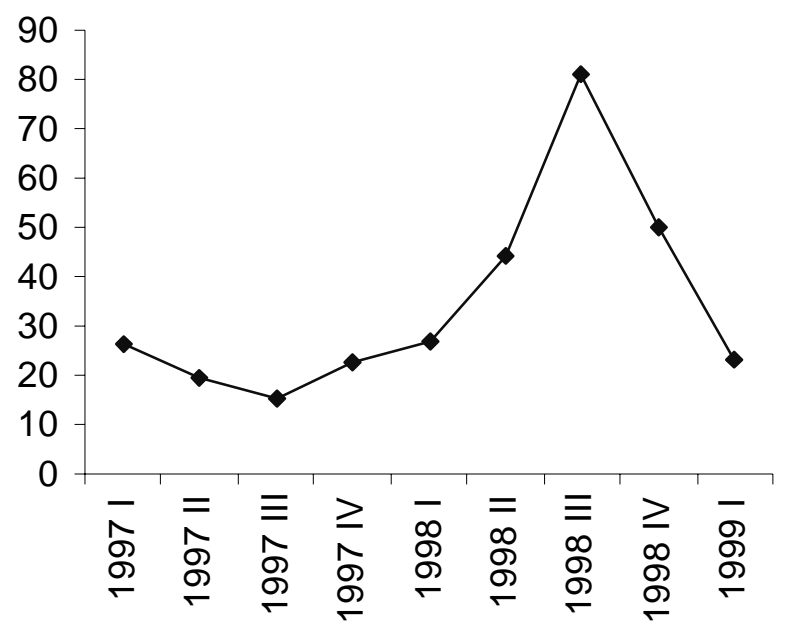


GRÁFICO 5 - COMPORTAMENTO DAS RESERVAS - TAILÂNDIA

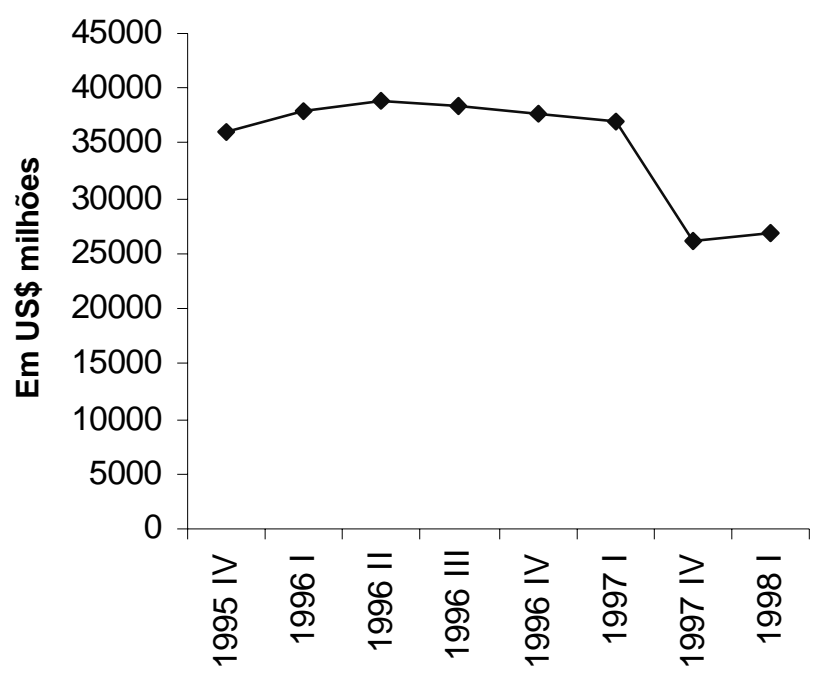

GRÁFICO 6 - TAXA DE JUROS (TAXA DO MERCADO MONETÁRIO TAILANNDIA)

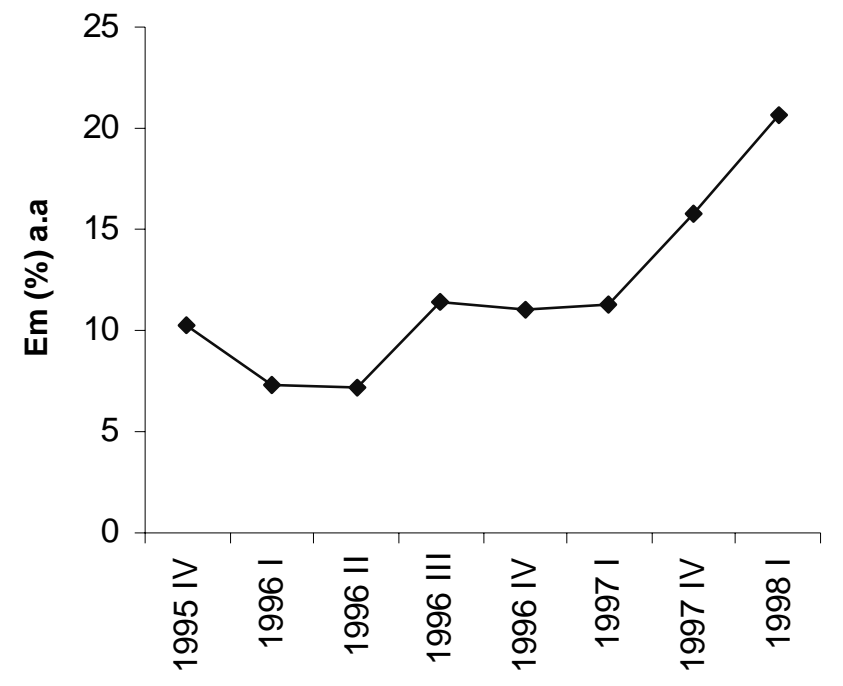


GRÁFICO 7 - COMPORTAMENTO DAS RESERVAS - MÉXICO

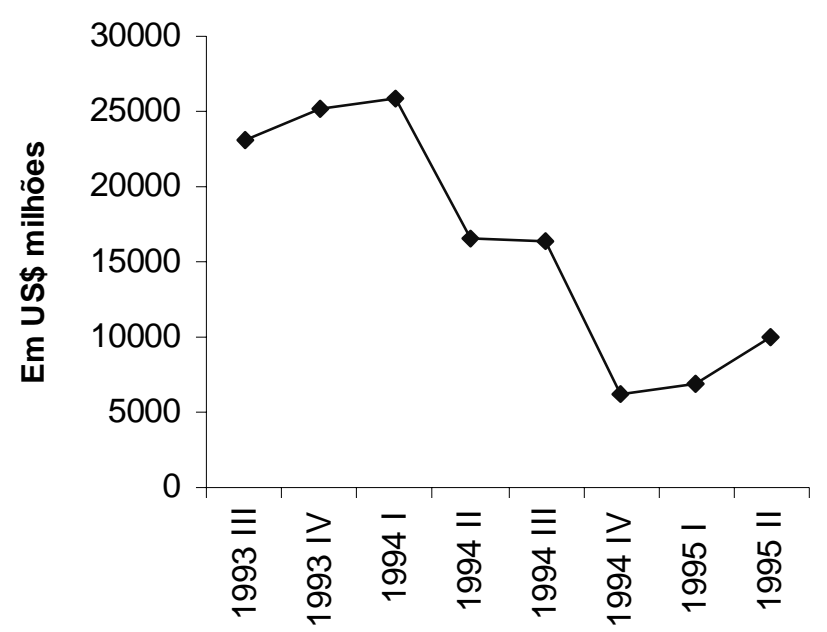

GRÁFICO \& - TAXA DE JUROS - MÉXICO (TAXA DO MERCADO MONETÁRIO - MÉXICO)

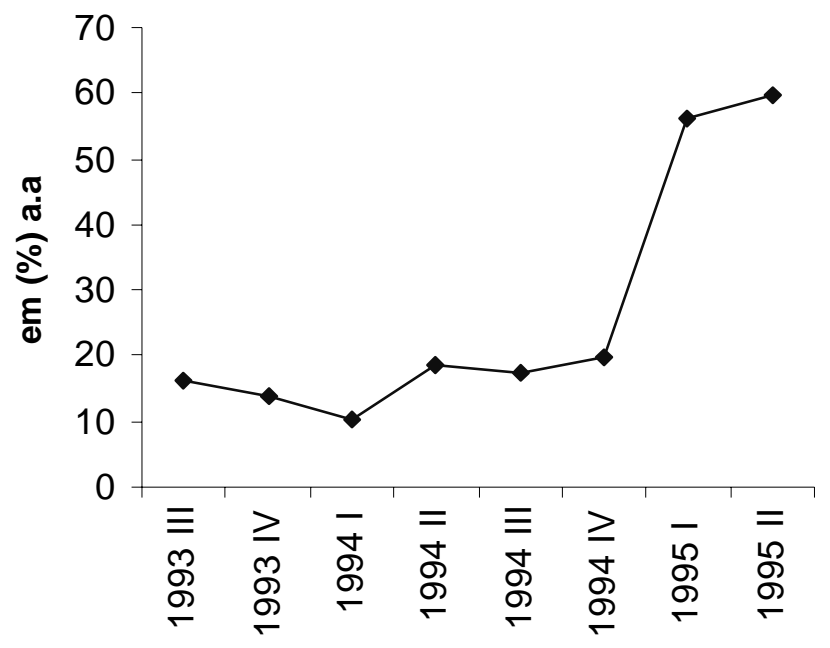


GRÁFICO 9 - COMPORTAMENTO DAS RESERVAS - BRASIL

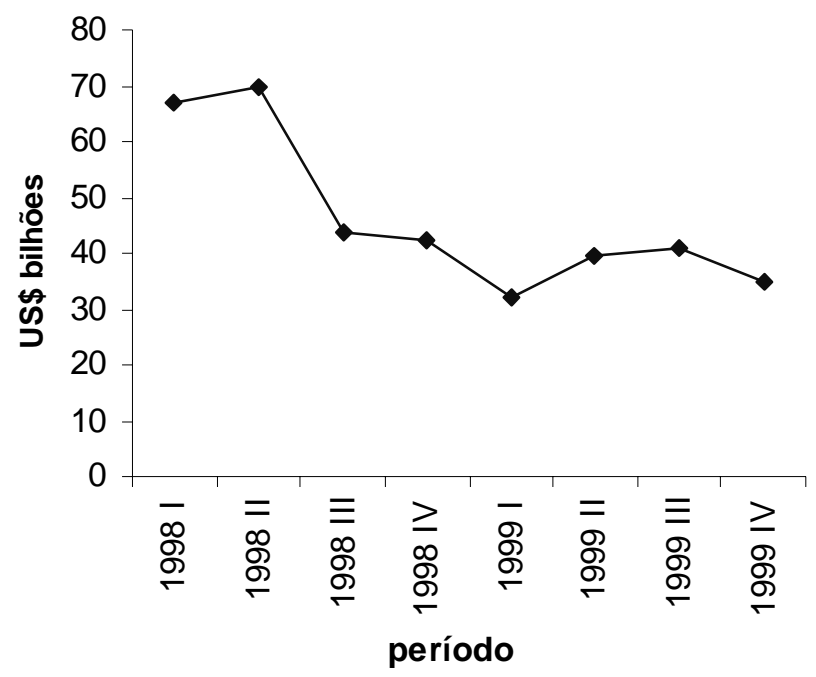

GRÁFICO 10 - TAXA DE JUROS - BRASIL (TAXA DO MERCADO MONETÁRIO)

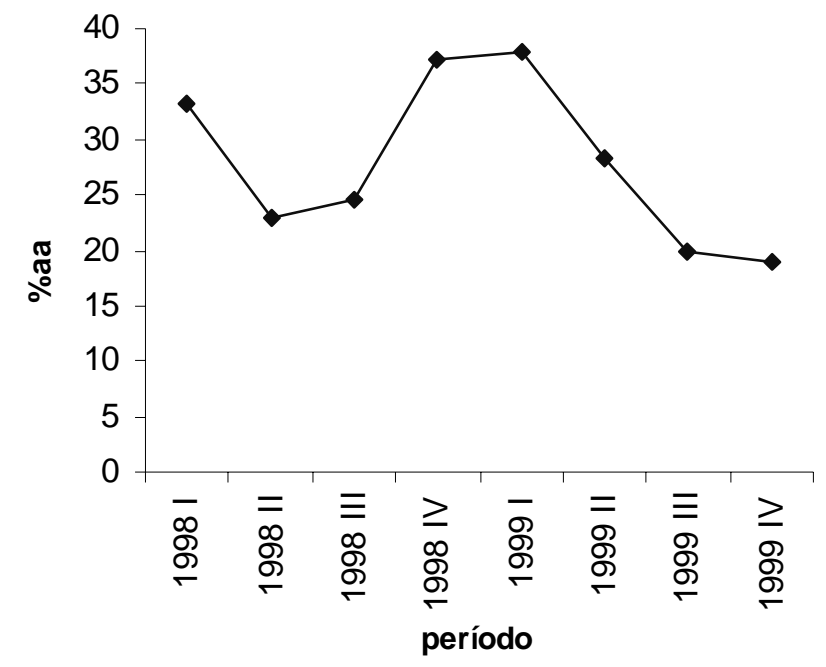

Fonte: FUNDO MONETÁRIO INTERNACIONAL - International Financial Statistics Diversos números. 